Check for updates

\section{London}

Cite this as: BMJ 2020;371:m4095 http://dx.doi.org/10.1136/bmj.m4095 Published: 21 October 2020

\title{
Covid-19: Suicidal thoughts increased in young adults during lockdown, UK study finds
}

\section{Jacqui Wise}

Rates of suicidal thoughts have increased during lockdown, especially among young adults, a longitudinal study has found. ${ }^{1}$

Research published in the British Journal of Psychiatry found that women, young adults, socially disadvantaged people, and people with pre-existing mental health problems reported the worst mental health outcomes in the initial six week period of national lockdown.

The study-funded by the Samaritans, the Scottish Association for Mental Health, and the Mindstep Foundation-claims to be the most detailed examination to date of the mental health of UK adults in the weeks after they were instructed to stay at home, on 23 March 2020. Researchers surveyed a national sample of 3077 adults three times from 31 March to 11 May. Participants have been followed up throughout the pandemic, and further results will be published in the coming months.

The study found that the proportion of respondents reporting that on at least one day in the previous week they had wanted to end their life increased from $8.2 \%$ to $9.2 \%$ and then to $9.8 \%$, over the three waves of the study. These rates were highest in young adults (aged 18-29), rising from $12.5 \%$ to $14.4 \%$ throughout the three waves. The authors note that direct comparisons cannot be made but that this past week rate is higher than an $11 \%$ past year suicidal ideation rate reported by young adults in another pre-covid-19 study.

\section{Vigilance}

Respondents from lower socioeconomic backgrounds were more likely to experience suicidal thoughts than those in higher socioeconomic groups, as well as respondents with pre-existing mental health conditions when compared with those without.

Rory O'Connor, lead author and chair in health psychology at the University of Glasgow, said, "The findings from our study, showing in particular the increasing rates of suicidal thoughts, especially among young adults, is concerning, and show that we must be vigilant to this at-risk group.”

Across all three blocks of time, one in four respondents $(26.1 \%)$ experienced moderate to severe levels of depressive symptoms. However, the study found that symptoms of anxiety, levels of defeat, and entrapment decreased over the six weeks of lockdown. Positive wellbeing also increased, while levels of loneliness did not change significantly.

One limitation of the study, the authors noted, is that it is based on self-reports rather than clinical diagnoses. They added that the sample was likely to underestimate the mental health effects of covid-19, as people who are digitally excluded may be under-represented.

The findings came as an investigation for the Guardian newspaper found a sharp rise in reports of sleep problems, eating disorders, and self-harm in under $18 \mathrm{~s} .^{2}$ Freedom of information figures showed that prescriptions for sleeping pills for under $18 \mathrm{~s}$ rose by $30 \%$ to 186 ooo from March to June 2020, when compared with two years ago. Adult prescriptions for sleeping tablets fell during the same period.

1 O'Connor R, Wetherall K, Cleare S, etal. Mental health and wellbeing during the covid-19 pandemic: longitudinal analyses of adults in the UK covid-19 Mental Health \& Wellbeing study. Br J Psychiatry 2020. doi: 10.1192/bjp.2020.212

2 Marsh S, Hill A. Figures lay bare toll of pandemic on UK children's mental health. Guardian 2020 Oct 21. https://www.theguardian.com/society/2020/oct/21/figures-lay-bare-toll-of-pandemic-on-uk-childrens-mentalhealth.

This article is made freely available for use in accordance with BMJ's website terms and conditions for the duration of the covid-19 pandemic or until otherwise determined by BMJ. You may use, download and print the article for any lawful, non-commercial purpose (including text and data mining) provided that all copyright notices and trade marks are retained. 